\title{
EL ACCESO DIFERENCIAL A LOS RECURSOS: EL AGUA POTABLE EN EL NOROESTE DE CÓRDOBA, ARGENTINA (1912-1930)*
}

\author{
The differential access to resources: drinking water in the northwest of \\ Córdoba, Argentina (1912-1930)
}

Loreta Giannone**

\section{Resumen}

La presente contribución es un primer avance en la indagación de los mecanismos y las estrategias que articularon las demandas sociales más inmediatas en torno a un conjunto de bienes y servicios distribuidos desigualmente en el espacio cordobés, durante la primera experiencia democrática que se inaugura en la provincia con la aplicación de la ley Sáenz Peña y que finaliza con el golpe de Estado de 1930. En esta oportunidad, se analizan los mecanismos que instrumentaron el acceso al agua potable considerando en concreto dos casos, representados por las localidades de Cruz del Eje y La Cumbre, ambas del noroeste cordobés. Asimismo, se reconstruyen las estrategias y los vínculos configurados por los agentes que ocupaban diferentes escalas del poder político (municipal, departamental, provincial y eventualmente nacional), sin perder de vista la agencia humana en los procesos de demanda, de reclamo y de búsqueda de soluciones a los problemas materiales de las localidades del noroeste provincial. Para la realización de este artículo se han consultado fuentes periodísticas provinciales y nacionales y los proyectos de ley presentados por los principales diputados nacionales y senadores de la provincia de Córdoba.

$<$ Desigualdad $><$ Recursos $><$ Agua potable $><$ Noroeste cordobés $>$

\begin{abstract}
The present contribution represents our first step in the research of the mechanisms and strategies generated by the immediate social demands, regarding a set of goods and services unevenly distributed in Córdoba during the first democratic experience. Such period began with the application of the Saenz Peña Law, and ended with the 1930 coup d'état. This article analyses the mechanisms that allowed the access to drinking water, considering two concrete cases: the cities of Cruz del Eje and La Cumbre, both located in the Northwest of Córdoba. Additionally, the paper reconstructs the strategies and bonds configured by the agents who belonged to different levels of political power (municipal, regional, provincial and, eventually, national), without overlooking the human action in the processes of demand and claim, and the search for solutions regarding material problems in the aforementioned cities. Diverse types of evidence have been used during the writing of this work such as provincial and national journalistic sources, as well as the bills submitted by the main national deputies and senators of the province of Córdoba.

$<$ Inequality $><$ Resources $><$ Drinking Water $><$ Northwest Of Córdoba $>$

Recibido: 15/07/2018//Aceptado: 06/09/2018

* $\quad$ Este trabajo forma parte del proyecto colectivo "Grupos sociales, diferenciación y desigualdad social en una sociedad heterogénea y cambiante. Córdoba, 1870-1995”, Subsidio Trianual (2016-2019), Secretaría de Investigación, Universidad Católica de Córdoba.

** Instituto de Estudios Históricos-Centro de Estudios Históricos "Prof. Carlos S. A. Segreti", Becaria Doctoral del Consejo Nacional de Investigaciones Científicas y Técnicas (CONICET), Argentina, loretagiannone@gmail.com
\end{abstract}


Giannone. El acceso diferencial a los recursos: El agua potable en el noroeste de Córdoba, Argentina (1912-1930).

\section{Introducción}

La indagación en torno a los problemas de acceso al agua potable adquiere significación histórica, al menos, por tres razones fundamentales. En primer lugar, porque se inserta en una trama más amplia que excede el ámbito local. Durante el período en que se inscribe este trabajo en América Latina se idearon múltiples proyectos que sentaron las bases del bienestar social y que involucraban a la totalidad del tejido social (Moreyra, 2015: 3-20).

En segundo lugar, la dinámica vincular que se configuró para resolver los problemas materiales en Cruz del Eje y La Cumbre, nos muestra una realidad compleja, al poner en relación las distintas esferas del poder político y sus múltiples intervenciones.

En tercer lugar y vinculado a lo anterior, permite identificar estrategias y prácticas sociales, visibilizar tensiones, disputas y los mecanismos políticos-partidarios de articulación de las demandas sociales específicas. En síntesis, revela una trama más amplia de significados que ayuda a comprender las motivaciones y los propósitos del comportamiento de los individuos y colectivos.

Este estudio, recupera una tendencia dominante de los últimos años presente en la historia social contemporánea que incorpora lo político al estudio de lo social, a través de la reintroducción del Estado a su propio terreno de investigación ${ }^{1}$ (Remedi y Barbosa, 2014: 9).

En esta línea de indagación se inscriben un conjunto de investigaciones que se han focalizado en el estudio del agua para explicar los conflictos y las tensiones suscitados entre diferentes actores con intereses específicos, recurriendo a una variedad de estrategias interrelacionadas y circunscriptas en un contexto regional. Si bien la literatura es extensa, para el caso de México algunos trabajos analizan la interconexión entre las diversas dinámicas del poder principalmente político, económico y social (Ávila García, 2002; Castro, Kloster y Torregrosa, 2004; Leyva Ávila, 2013). En nuestro país para el mismo período las investigaciones se dedicaron a los principales problemas de acceso a los recursos desde un abordaje que incorpora la relación entre las dinámicas ambientales y sociales, sin perder de vista de qué manera el discurso atravesaba las concepciones en torno a los usos del agua (Radovanivic y Tartarini ,1999; Rojas y Saldi, 2010; Isuani, 2011).

En Córdoba, los enfoques recuperan las diversas dinámicas abordando la problemática desde la lógica del conflicto; algunas de las principales líneas de indagación que se dedican a un estudio pormenorizado sobre el agua potable durante el período que abarca este trabajo se concentran particularmente en la ciudad de Córdoba (Solveira, 2009: 30-70) y en la región del noroeste y la serranía cordobesa (Remedi, 2006; Sturla, 2011; Garnero, 2014 y 2018). Todas estas indagaciones priorizan las relaciones existentes entre dinámica social y política, sin perder de vista de qué manera el discurso

\footnotetext{
Si bien se alude a la existencia de un estado de matriz liberal -dado el relativo grado de consenso que existe en torno a dicha caracterización- por referencia a situaciones históricas concretas y específicas, se recurre a deslizamientos semánticos, tales como "estado gendarme liberal" o "estado de corte intervencionista".
} 
higienista y modernizador de la época atravesaba las prácticas y los comportamientos de los agentes estatales y de la población local.

Siguiendo la senda trazada por la literatura histórica, el presente artículo examina cómo los sujetos (portadores de intereses y prácticas sociales específicas) exploraron las más diversas formas de gestión de las políticas públicas en el interior provincial. Además, no se pierden de vista los aportes de la nueva historia política para explicar de qué manera los actores sociales desplegaban prácticas, estrategias y mecanismos que excedían el mero reclamo por el agua potable. Este enfoque analítico lleva a deslizar nuestro interés desde el estudio de los partidos políticos y sus múltiples estrategias de cooptación de un "potencial votante", hacia una historia política configuracional ${ }^{2}$. Al insertar la demanda en la dinámica política, los ciudadanos redefinieron los espacios, las formas de ejercer la ciudadanía y los mecanismos específicos de configuración de la autonomía municipal

El presente estudio relaciona niveles diferenciados e íntimamente vinculados de la realidad histórica, al insertar la indagación en una lógica que incluye la dinámica socio-política del reclamo, lo que justifica en parte la selección temporal adoptada en esta instancia. Asimismo, revela una configuración diferente de los grandes procesos históricos que tuvieron lugar en las primeras décadas del siglo XX. Al ubicar la modernización y la experiencia de la democratización de la provincia de Córdoba a escala humana, las dinámicas estudiadas se presentan como parte de un mismo fenómeno observable a través del comportamiento de los individuos.

El artículo se divide en tres partes. La primera, en la que se abordará de manera esquemática y descriptiva el ordenamiento y clasificación espacial realizado por el Estado cordobés en el marco de la modernidad liberal. La segunda, donde se explicarán -a grandes rasgos- las representaciones de las elites en torno a la noción de bienestar y el marco legal instrumentado por el Estado para achicar las desigualdades regionales observadas en el acceso a los bienes y servicios en el interior provincial. En tercer término, se analizarán las prácticas articuladas por los ciudadanos y los agentes estatales identificando la demanda formulada por las poblaciones del noroeste de la provincia de Córdoba (Cruz del Eje y La Cumbre) y las estrategias desplegadas por los sujetos en los procesos de gestión, de intervención y de resolución, al menos parcial, de la problemática señalada. Se trabajará con la red de resolución de dichos problemas, ${ }^{3}$

\footnotetext{
2 Ver: Barriera, D. (2002). "Por el camino de la historia política: hacia una historia política configuracional", Secuencia, México, ${ }^{\circ} 56$. Por su parte, Andrea Reguera ha compilado un libro dedicado al análisis de las redes sociales a través de la configuración de vínculos entre los sujetos. Este estudio aborda la dinámica vincular como herramienta analítica para asociar las prácticas políticas, sociales y culturales en contextos históricos diferenciados. (Reguera, 2017).

3 Sin perder de vista el enfoque más amplio y laxo de la categoría redes sociales que no sólo responde a la resolución de problemas materiales de la población en un espacio y tiempo específicos, esta contribución recurre al concepto de "redes de resolución de los problemas", categoría acuñada por el sociólogo Javier Auyero (2011: 12-24), quien la utiliza para estudiar el proceso de intercambio que se generaba entre los sujetos que participaban de la red clientelar en el marco de relaciones desiguales de poder. Si bien el autor se refiere a la misma para analizar de qué manera los pobres gestionaban los recursos necesarios para resolver los problemas más inmediatos de su entorno, su utilización no deja de ser apropiada para
} 
Giannone. El acceso diferencial a los recursos: El agua potable en el noroeste de Córdoba, Argentina (1912-1930).

prestando atención al comportamiento de los actores que intervenían en la búsqueda de posibles soluciones y los mecanismos que utilizaban para resolver los problemas vinculados a la desigual distribución de recursos. En este marco, resulta apropiado el modelo aportado por Luis Reygadas (2008) en torno a los procesos de configuración de la desigualdad. El autor sostiene que la desigualdad no puede comprenderse al margen de las relaciones de poder, por lo que resulta clave analizarla desde una perspectiva relacional. Según Reygadas (2004 y 2008), la distribución de bienes sólo se comprende en determinadas configuraciones estructurales a partir de la interacción entre los agentes que se disputan la apropiación de los bienes y desde un enfoque que entrecruza diversas dinámicas históricas.

Asimismo, se estudiará el interés político que suscitaba el abastecimiento de agua potable en las localidades mencionadas, teniendo en cuenta la particular preocupación que mostraba la elite dirigente en la resolución de la problemática expuesta. Sin descuidar la intervención de un grupo empresarial con intereses económicos en la región, ${ }^{4}$ el análisis se centra en la indagación del comportamiento político de los actores a través de las disputas que se generaron entre los representantes de las diversas escalas del poder político y los ciudadanos a raíz del reclamo por un servicio de aguas corrientes.

\section{Una desigualdad macro: el ordenamiento económico y social del espacio cordobés realizado por el Estado Provincial}

Durante la modernidad liberal ${ }^{5}$ el Estado provincial ordenó su vasto territorio siguiendo la lógica inclusión-exclusión de los espacios regionales en los procesos de integración económica, política y social, separando zonas productivas en función de las "ventajas comparativas". En ese ordenamiento de las áreas productivas quedaron excluidos aquellos departamentos que -por sus condiciones de economía colonial- se

explicar de qué manera estas redes facilitaron el acceso a una serie de bienes materiales, como por ejemplo, aunque no exclusivamente el agua potable.

${ }^{4}$ Dados los límites de extensión impuestos para este trabajo, en esta oportunidad no se incluyen las vinculaciones existentes entre las elites estatales y las corporaciones económicas, principalmente en relación a la intervención empresarial en aquellas obras públicas de mayor envergadura. No obstante, no se pierde vista de qué manera operó la lógica económica y los beneficios que traía aparejado para el sector empresarial, la construcción de obras de irrigación en Cruz del Eje (Dique Cruz del Eje) y la de una importante hotelería destinada a absorber la demanda de turismo en el Valle de Punilla -concretamente en La Cumbre- por medio de la ampliación del sistema de aguas corrientes.

5 Concepto acuñado por Sarlo para caracterizar el impacto de la modernización en las condiciones de vida de los diversos sectores sociales en las principales ciudades de América Latina entre fines del siglo XIX y las primeras décadas del XX. Moreyra ha utilizado este concepto para referirse a las transformaciones ocurridas en la provincia de Córdoba, el rol del Estado y de las instituciones de la sociedad civil frente al crecimiento, la crisis y los desajustes sociales. Siguiendo el análisis de la autora, la provincia de Córdoba experimentó un proceso de transición hacia la modernización exteriorizado en el anhelo de lograr una transformación económica, el progreso material y una sociedad ordenada, integrada, saludable y culta. No obstante ese proceso económico no estuvo acompañado por una redistribución significativa del poder y de la riqueza, sino, que por el contrario involucró la marginación y la exclusión del vastos sectores sociales que experimentaron en sus vidas necesidades básicas insatisfechas y la ausencia de oportunidades que impedían el desarrollo integral y participativo de los ciudadanos (Moreyra, 2009). 
desarticularon de la provincial, afectando las posibilidades concretas de acceso a los principales recursos y bienes básicos que garantizaban su progreso material.

Esta situación derivó en importantes asimetrías regionales. La zona conformada por los departamentos del este y del sur consiguió insertarse plena y exitosamente en el modelo económico dominante, lo que se tradujo en un significativo crecimiento económico. En contraposición, la zona norte y oeste quedó rezagada, permaneciendo en gran medida al margen de dichas transformaciones y experimentando otras de signo contrario, de marginalidad económica y atraso (Remedi, 2006, 25-30).

A diferencia de lo sucedido en la Capital y en la zona pampeana de la provincia, el área abordada se inserta en un entramado geográfico (noroeste y serranía cordobesa) caracterizado por una dinámica poblacional y socio-económica relativamente homogénea, manifestando un claro retroceso en sus variables de población y de economía. No sólo concentraba el menor porcentaje de la población, que por el flujo de las migraciones internas se trasladaban al sudeste provincial, sino que las actividades económicas atravesaban un período de franco estancamiento (Giannone, 2014: 50).

Sin embargo, para los casos seleccionados cabe resaltar un rasgo distintivo, que permite comprender la política de construcción de obras públicas del Estado. Siguiendo el análisis de la prensa oficialista, ${ }^{6}$ ésta caracterizaba a la región que se extendía desde el Dique San Roque hasta Cruz del Eje como el primer atractivo turístico del país ${ }^{7}$. Este interés particular en el desarrollo del turismo se vinculaba con la iniciativa de una elite dirigente que proponía la integración económica de aquellas regiones tradicionalmente postergadas $^{8}$.

De las localidades analizadas, Cruz del Eje, ubicada entre la serranía cordobesa y la desértica gran depresión de las Salinas Grandes, era la ciudad con mayor actividad económica y con una dinámica poblacional relativamente más diversificada que el resto de la región ${ }^{9}$. En las postrimerías de la década del 20 alcanzaría los 12 mil habitantes, ${ }^{10}$ y si bien poseía un importante núcleo de población rural, su temprana concentración urbana le permitió convertirse desde comienzos del siglo $\mathrm{XX}$ en un fuerte atractivo económico y turístico para la zona, contando a su vez con un amplio desarrollo

\footnotetext{
${ }^{6}$ Me refiero al diario El País, fundado en 1926 por el dirigente conservador Ramón J. Cárcano, con el objetivo de dar a conocer la labor administrativa del Partido Demócrata en sus diferentes áreas (política, social y económica).

7 Hemeroteca de la Legislatura de Córdoba (en adelante HLC). El País, 1927, enero 1, p.5.

${ }^{8}$ Elisa Pastoriza en un trabajo sobre la historia del turismo en Argentina, dedica un importante apartado al análisis de la conformación del turismo en las sierras cordobesas desde fines del siglo XIX y comienzos del XX. En este sentido, la autora resalta la vinculación existente entre el tendido del ferrocarril Central Argentino que permitió la conexión entre Buenos Aires y las sierras cordobesas, con el desarrollo turístico de la zona serrana de la provincia (Paztoriza, 2010).

9 El Censo poblacional de 1914 exhibe para el departamento Cruz del Eje un total del 4\% de la PEA (población económicamente activa). En términos comparativos, poseía el mayor porcentaje de la región. Anuario de Estadísticas y Censos. Tercer Censo Nacional levantado el 1 de junio de 1914, Tomo 2: Población, 1916. (en adelante AEC).

${ }^{10}$ En 1928, el senador demócrata por Cruz del Eje elevó a la legislatura provincial un proyecto de ley para declarar ciudad a la localidad aludida.
} 
Giannone. El acceso diferencial a los recursos: El agua potable en el noroeste de Córdoba, Argentina (1912-1930).

político-administrativo (Municipalidad, ${ }^{11}$ Comisaría General, Registro Civil, Correos, Telégrafos, Juzgados de Paz, Receptoría de Rentas, Distrito Militar, Escuela Normal, Escuela Municipal y varias elementales, una sucursal del Banco de la Nación y del Banco Español del Río de la Plata), ${ }^{12}$ que favoreció su diversificación socio-ocupacional.

En su tesis doctoral sobre la expansión ganadera y agrícola en la provincia de Córdoba, Moreyra (1992) ha establecido una importante discriminación entre aquellas regiones económicamente activas -dadas las condiciones favorables impuestas por el mercado internacional- y las zonas marginadas de dicho proceso, como el norte, oeste y noroeste cordobés. En su investigación, la historiadora cordobesa dedica un peculiar análisis al caso de Cruz del Eje, que junto con otras poblaciones de la región contaron con diferentes instancias de intervención del Estado en la construcción del Dique Villa Cruz del Eje, dentro una política pública en torno al uso del agua para consumo local y para el desarrollo económico regional. Según Moreyra (1992), estas etapas de intervención estatal datan de fines del siglo XIX y pesar de los diversos proyectos de ley elevados por diputados provinciales demócratas y radicales, contando a su vez con el apoyo del Ejecutivo Provincial (el gobernador demócrata Cárcano en 1912 y 1924 respectivamente y Borda, dirigente radical, para el período gubernativo que se extiende entre 1915 y 1918) los planes de irrigación por medio de la construcción del dique no se concretaron.

Por su parte, La Cumbre, ubicada en el departamento Punilla, en la serranía cordobesa y a $80 \mathrm{~km}$ de la Capital, era la segunda ciudad más poblada. ${ }^{13} \mathrm{~A}$ fines del siglo XIX, con la afluencia de inmigrantes, se transformaría su perfil social. La sociedad pastoril de 155 habitantes según el censo nacional de 1895 daría lugar a una comunidad de activos ciudadanos que en las primeras décadas del siglo XX se organizarían alrededor de la construcción de una escuela y su iglesia ${ }^{14}$.

Este ordenamiento espacial lleva a mencionar el segundo mecanismo de desigualdad territorial, que se asociaba a las múltiples estrategias desplegadas por el Estado para articular las distintas regiones de la provincia con el centro urbano capitalino, donde radicaba el poder político central. Ese criterio de clasificación incidió en los vínculos que se construían entre la capital y el ámbito departamental y entre éste y su población, activando mecanismos de distribución de recursos (bienes, servicios, obras públicas, etc.) siguiendo la lógica implícita del privilegio que se otorgaba a cada región.

Finalmente, y aunque no se analice en este artículo, el desigual acceso al agua potable estuvo condicionado por la específica dinámica socio-ambiental de la región noroeste, caracterizada por su irregularidad climatológica (sequías estacionales) ${ }^{15}$.

\footnotetext{
${ }^{11}$ A partir de la segunda mitad del siglo XIX el gobierno provincial fue incentivando la formación de núcleos de población para ordenar y afirmar su control sobre el territorio. Así es que emergieron localidades y se formaron municipalidades en Villa Dolores, San Pedro, Cruz del Eje, San Carlos Minas, Pocho, entre otros. (Garnero, 2017: 12).

${ }^{12}$ HLC. "La sierra, de Córdoba a Cruz el Eje. Proyecto para declarar ciudad a Cruz del Eje", (1 de enero de 1927), El País, p. 1-5.

${ }^{13}$ En 1927 La Cumbre contaba con cinco mil habitantes.

${ }^{14}$ AEC. Segundo Censo Nacional levantado el 10 de mayo de 1985, Tomo 2: Población, 1895.

${ }^{15}$ Gabriel Garnero (2018) ha trabajado la relación entre dinámicas ambientales y sociales en los problemas
} 


\section{El discurso y las prácticas de las elites estatales en torno al acceso al agua potable en el noroeste cordobés}

En 1916, La Mañana se hacía eco de los principales problemas derivados de la escasez de agua potable en el país. Con un perfil editorial que podríamos calificar, con algunos matices, de conservador, su análisis nos da una imagen, al menos parcial, de la representación hegemónica que imperaba entre las elites estatales de entre siglos, en torno a los bienes materiales esenciales para garantizar el bienestar de los ciudadanos y reducir de este modo los niveles de desigualdad regional existentes en las primeras décadas del siglo $\mathrm{XX}^{16}$.

En el fragmento extraído de su columna editorial es posible observar algunas de las ideas que permeaban el discurso y las preocupaciones de los diferentes sectores dirigentes. En primer lugar, la importancia de que el Estado garantizara el bienestar de la población por medio del acceso al agua potable, respondiendo a su vez a los temores de las clases altas por la propagación de enfermedades infecto-contagiosas. En esta línea, el periódico sostenía: "la higiene, factor imprescindible, necesita del agua a la que debe sus mejores resultados y en este sentido es la única manera de evitar el acrecentamiento de la mortalidad y fijar de una manera estable en la población un estado sanitario satisfactorio" $"$.

Aunque predominaba el enfoque higienista, el agua potable comenzaba a constituirse en un bien esencial, y por extensión en un derecho inalienable de las personas. Al respecto, La Mañana señalaba: "El agua es un elemento cuyo consumo no puede limitarse sin lesionar la colectividad en sus derechos esenciales de vida, es cuidar por todos los medios de implantar un servicio de aguas corrientes amplios, sin limitación ni trabas en las tarifas de precio"18.

Para un Estado de matriz liberal, el "bienestar" era, ante todo, una responsabilidad individual; sin embargo, dentro de esta tendencia general existían excepciones. Como una de sus misiones primordiales, se proponía velar por la seguridad física y patrimonial de los ciudadanos, por extensión, darles también ciertas garantías higiénico-sanitarias (Remedi, 2006: 26-35).

A través de los instrumentos legales y de los múltiples agentes que gestionaban el aprovisionamiento de recursos hídricos en aquellos departamentos de la provincia en donde la escasez de agua potable era realmente acuciante, se comenzó a delinear

derivados de la escasez y/o del exceso de agua en las poblaciones del noroeste provincial, concretamente en la serranía cordobesa. Según el autor, la región (estudia principalmente la Cuenca del río de los Sauces en el valle de Traslasierra), poseía un régimen de precipitaciones que afectaba el acceso al agua para el consumo y para las principales actividades económicas.

${ }^{16}$ La lectura en clave cultural de la historia social, nos adentra a los significados y valores que subyacen en las prácticas dirigidas a la construcción de las políticas sociales. En este caso, a través del análisis editorial de la prensa conservadora, podemos acercarnos a las representaciones de los actores, al menos de un sector de los mismos, en torno a los niveles de bienestar que debía alcanzar la sociedad en su conjunto (Moreyra, 2015).

${ }^{17}$ Biblioteca Nacional Mariano Moreno. (en adelante BNMM). "El Agua Potable.” (22 de febrero de 1916), La Mañana, p. 6.

${ }^{18}$ BNMM. "El agua potable”, (22 de febrero de 1916), La Mañana, p. 6. 
Giannone. El acceso diferencial a los recursos: El agua potable en el noroeste de Córdoba, Argentina (1912-1930).

una política intervencionista, destinada a achicar las diferencias existentes entre las regiones, es decir, para velar por el bienestar de sus ciudadanos.

En este marco, en 1917 se proyectaba una ley que prohibía la perforación de pozos que se alimentaran con napas de aguas surgentes y semisurgentes, debido a la contaminación que ellos provocaban ${ }^{19}$. Sin embargo, no fue hasta 1925 cuando se tomó mayor conciencia de las implicancias sociales y económicas que esta práctica suponía, subrayando el desinterés de los propios beneficiarios ${ }^{20}$.Ante estos inconvenientes, se garantizaba el sistema de extracción por medio de una normativa que exigía la autorización previa a los organismos del poder político provincial ${ }^{21}$.

No obstante, existían otros motivos que explicaban la iniciativa legislativa. El desarrollo y el progreso material del área tradicionalmente marginada de los procesos económicos de integración, llevó a que en 1927 a que el Poder Ejecutivo enviara a la Legislatura otro proyecto de ley referido al aprovechamiento del caudal de los ríos y caídas de agua de las sierras para incentivar el crecimiento económico en el noroeste cordobés. El argumento que lo fundamentaba resaltaba el aprovechamiento de esa energía hidráulica para resolver los problemas económicos más acuciantes y asegurar el bienestar de toda la humanidad. ${ }^{22}$ De esta manera, el agua de las sierras sería utilizada para la irrigación de las tierras de agricultura, el desarrollo de energía hidráulica y para toda aquella actividad que beneficiara económicamente a la región y a la provincia en su conjunto ${ }^{23}$.

El viraje producido en la política de obras públicas se observa en el discurso de los gobernadores y de los dirigentes políticos, que sostenían la importancia de fomentar el desarrollo material y el progreso de los departamentos del noroeste, y en las excursiones y giras políticas por el interior cordobés, que contaban con una comitiva encabezada por el Gobernador y su Ministro de Obras Públicas ${ }^{24}$.

Concretamente, esta política activa incluía la creación de comisiones encargadas de visitar y estudiar las necesidades materiales de los departamentos, ${ }^{25}$ la elaboración de inventarios para supervisar las obras de mayor envergadura, ${ }^{26}$ la aprobación de contratos con empresas privadas para la construcción de puentes, caminos, servicios de luz eléctrica

\footnotetext{
${ }^{19}$ Archivo del Arzobispado de Córdoba (en adelante AAC). Los Principios, "Pozos Surgentes", 1 de junio de 1917, p. 6.

${ }^{20}$ HLC. "El sistema de extracción", (10 de septiembre de 1917), El País, p. 12.

${ }^{21}$ HLC. "El sistema de extracción, (10 de septiembre de 1927), El País, p. 5.

${ }^{22}$ HLC. "Córdoba tiene abundantes fuentes de energía hidro-eléctricas", (1 de enero de 1927), El País, p. 5.

${ }^{23}$ HLC. "Córdoba tiene abundantes fuentes de energía hidroeléctricas", (1 de enero de 1927), El País, p. 5.

${ }^{24}$ AAC. "Aguas corrientes. Para Deán Funes y Totoral", (7 de octubre de 1918), Los Principios, p. 8. HLC. "Obras públicas". (25 de febrero de 1928), La Nación, p.2. HLC. "Provisión de agua potable", (27 de febrero de 1928), La Nación, p. 3. HLC. "Provisión de agua potable", (19 de mayo de 1918), La Nación, p.5.

${ }^{25}$ HLC. "Córdoba. Plan de Obras Públicas a desarrollarse en el próximo año", (18 de octubre de 1924) La Prensa, p.8.

${ }^{26}$ HLC. "Se hará un inventario del dique. Como consecuencia del decreto, quedó suspendido todo el personal de inspección”. El País, (21 de abril de 1927) p.7.
} 
en las localidades más despobladas del norte, ${ }^{27} \mathrm{y}$ la de un amplio presupuesto destinado a la construcción de hospitales, obras de irrigación y servicios de aguas corrientes ${ }^{28}$.

Aunque el marco legal que fundamentaba esta intervención nos permite conocer de qué manera el Estado resolvía los problemas sociales de la época, ${ }^{29}$ no nos informa sobre las específicas estrategias utilizadas por los ciudadanos, no nos detalla acerca de las disputas que se generaban alrededor del control de los mecanismos que posibilitaban la gestión del recurso hídrico, sobre los vínculos que se tejían en torno al acceso al agua y las motivaciones y propósitos que subyacían al comportamiento de los actores sociales.

A continuación, se analizará este proceso prestando atención a las prácticas de los sujetos y las disputas políticas que se suscitaron en torno al suministro de agua en las localidades de Cruz del Eje y La Cumbre.

\section{Un acercamiento micro-analítico ${ }^{30}$ a los procesos de gestión por el acceso al agua potable}

La integración económica del área abordada a través de la explotación turística del Valle de Punilla y de Cruz del Eje y su dinamismo socio-económico alcanzado, permite visibilizar el activo comportamiento de los sujetos que -recurriendo a una multiplicidad de prácticas y estrategias- resolvían sus problemas más inmediatos.

La demanda inicial de los ciudadanos de Cruz del Eje y de La Cumbre por la instalación de un servicio de aguas corrientes activó diferentes mecanismos de intervención de los organismos estatales provinciales en sus diferentes instancias (legislativas, ministeriales y ejecutivas) en el marco de una intrincada relación entre elites estatales de las más altas esferas del poder, autoridades locales y beneficiarios ${ }^{31}$.

${ }^{27}$ HLC. "Contratos aprobados". El País, (20 de abril de 1927), p.3. HLC. "Provisión de agua y perforaciones en la campaña”. El País, (1 de enero de 1927), p. 6.

${ }^{28}$ Entre 1924 y 1925 la legislatura provincial debatió el presupuesto destinado a la realización de obras públicas en el interior provincial. Dentro del mismo, cabe mencionar el fuerte financiamiento asignado al desarrollo de obras públicas para los departamentos del norte. Biblioteca de la Legislatura de la Provincia de Córdoba (en adelante BLPC). Diario de Sesiones Cámara de Diputados, Legislatura Provincial, $12^{\circ}$ sesión ordinaria: 18 de abril de 1924. "Presupuesto de obras de infraestructura".

${ }^{29}$ En losúltimos años la historiografía local ha revalorizado el papel del Estado en las diferentes problemáticas sociales con antelación a la emergencia del peronismo. Por un lado, un grupo de investigaciones que vinculan las esferas del mundo social y político con el aparato estatal centralizado. Dentro de estas líneas de indagación cabe mencionar aquellas concentradas en la articulación de las demandas sociales a través de las sociedades de beneficencia, las instituciones eclesiásticas y confesionales (Moreyra, 2009; 2015; 2017 y Moretti, 2014). Por el otro, se han abierto nuevas líneas recientes de investigación que han avanzado significativamente en la construcción de las políticas sociales en el interior cordobés (Ortiz Bergia, 2009) y en los espacios rurales (Ruffini y Salomón, 2013, 30-40).

${ }^{30}$ La categoría microanalítica utilizada en este trabajo se inspira en la lectura de un conjunto de ensayos de algunos reconocidos historiadores que en el marco de la crisis del paradigma cuantitativo hegemónico, recuperaron en sus estudios las perspectivas antropológicas interesadas en los enfoques cualitativos y en sus dimensiones subjetivas para la indagación de la historia argentina entre 1870 y 1930 desde la lógica regional, relativizando algunos presupuestos teórico-conceptuales relativamente extendidos entre la comunidad de historiadores (Bragoni, 2004).

${ }^{31}$ A través del registro documental es posible identificar no sólo la demanda y el constante reclamo de la ciudadanía por obras públicas (caminos, puentes, escuelas, hospitales, servicios de luz eléctrica, agua 
Giannone. El acceso diferencial a los recursos: El agua potable en el noroeste de Córdoba, Argentina (1912-1930).

El reclamo de los vecinos en Cruz del Eje se insertaba en esta lógica y respondía a la iniciativa combinada y articulada de los agentes estatales representantes de las diferentes escalas del poder político ${ }^{32}$.

En esta trama de relaciones, en 1915 el diputado nacional por el Partido Demócrata Juan F. Cafferata realizó una visita de inspección por los departamentos serranos, entre los que se encontraban las Villas de Cruz del Eje y de Dolores (Departamento San Javier). Apoyado en un saber técnico y especializado en el área de la medicina, Cafferata elaboró un diagnóstico preciso sobre los principales problemas vinculados a la falta de agua potable en la región. Desde un discurso que podríamos calificar de higiénico-sanitario, el dirigente demócrata detallaba el conjunto de enfermedades que provocaban los "sistemas primitivos" utilizados como fuente de suministro de agua en las localidades mencionadas: "la mala provisión de agua, con sistemas primitivos, se traduce en enfermedades como la tifoidea, que reina endémica; como el paludismo, mantenido por canales abiertos donde el mosquito encuentra fácil vivienda y por otros inconvenientes que han de ir acentuándose a medida que aumente la densidad de la población" ${ }^{33}$.

Este análisis articulaba el principal argumento del proyecto de ley de aprovisionamiento de agua potable a las localidades de Villa Cruz del Eje y Villa Dolores, presentado en la Cámara de Diputados de la Nación por el dirigente demócrata.

Por su parte, los ciudadanos activaban sus propios mecanismos resolutivos ante el problema. A tres años del petitorio inicial elevado al Gobernador provincial, ${ }^{34}$ la población de Cruz del Eje realizaba el reclamo por la inmediata instalación del servicio de aguas corrientes en la ciudad. Los vecinos de la localidad de Cruz del Eje resolvieron realizar una pública manifestación de protesta. "En la concentración pública, realizada

potable), sino además el diseño y la ejecución de un conjunto de estrategias de acción desplegadas por los actores sociales que recurrían a diferentes mecanismos de interpelación y exhortación a los poderes públicos provinciales, afianzando las bases de una cultura asociativa que no se limitaba a las localidades estudiadas en esta ocasión. La prensa provincial (Los Principios, La Voz del Interior y El País) y nacional (La Prensa y La Nación) y la documentación oficial conservada en el fondo documental de Gobierno, poseen un abultado y sólido material para abordar la dinámica específica del reclamo por servicios y obras públicas y las vinculaciones con el poder político provincial como mecanismo de articulación de las demandas sociales, no solo para los casos de Cruz del Eje y de La Cumbre sino para el conjunto de los departamentos, acercándonos a una realidad atravesada por la complejidad del fenómeno y la multiplicidad de respuestas ante los problemas materiales presentes en el interior cordobés.

${ }^{32}$ HLC. "Una delegación de Cruz del Eje se entrevistó con el gobernador". (16 de febrero de 1913), La Voz del Interior, p. 6.

${ }^{33}$ BLPC. Diario de Sesiones de la Cámara de Diputados, Congreso Nacional, 1915. tomo 2, 7: Provisión de agua potable a las Villas de Dolores y Cruz del Eje. Juan F. Cafferata y otros. Sobre las problemáticas vinculadas a la salud pública, Adrián Carbonetti (2014) ha analizado extensamente las principales problemáticas en torno a la salud pública y la enfermedad en la provincia de Córdoba con un enfoque que inserta la historia regional en una perspectiva nacional y latinoamericana. Por su parte, Fernando Remedi (2006) ha analizado, en el marco de su tesis doctoral, los principales problemas de acceso y abastecimiento de agua en las localidades del noroeste cordobés, destacando la importancia de Juan F. Cafferata en la elaboración de un diagnóstico preciso sobre dichas problemáticas.

${ }^{34}$ HLC. "Cruz del Eje solicita servicios de aguas corrientes". (15 de septiembre de 1913) La Prensa, p. 5. 
en la plaza central se congregó una multitud de ciudadanos reclamando por la instalación de aguas corrientes en la ciudad" 35 .

La manifestación se vinculaba con estrategias de gestión de aquellos sujetos que siendo representantes del poder provincial en las instancias departamentales y municipales, fortalecían las actividades de los ciudadanos y obtenían beneficios para la localidad en el mediano plazo. La intervención simultánea del jefe político departamental y el intendente municipal ante el Poder Ejecutivo provincial facilitó la inmediata resolución del problema ${ }^{36}$.

Una segunda estrategia a la que recurrieron los ciudadanos fue la creación de la Comisión de Vecinos de Cruz del Eje. Entre sus objetivos más inmediatos se encontraba la búsqueda de adhesiones y apoyos entre los ciudadanos de las localidades aledañas para exhortar a los agentes estatales -Ministro de Obras Públicas y el Gobernador- al cumplimiento de las obras de irrigación proyectadas sobre los ríos Cruz del Eje, Soto y Pichanas ${ }^{37}$.

Los programas de modernización del noroeste cordobés impregnaron no sólo el discurso y las prácticas de las elites dirigentes, sino que además fueron incorporados y adaptados por la propia sociedad, o al menos por un sector de la misma, que apoyaba aquellas obras públicas dirigidas a activar su economía.

En este marco se insertaba el proyecto de ley presentado en 1911 por el diputado por Cruz del Eje, Rodríguez de la Torre, subrayando la necesidad de propiciar el crecimiento económico de su ciudad por medio de un sistema de regadío que incrementara el desarrollo de la producción de uva en la localidad. El mismo contaba con el apoyo de 31 ciudadanos, quienes serían los principales beneficiarios de la iniciativa ${ }^{38}$. A pesar de la renuencia de un sector de legisladores a aprobar la propuesta, ${ }^{39}$ finalmente, por amplia mayoría se votó a favor ${ }^{40}$.

En 1919 otra iniciativa legislativa provincial reanudó los planes de construcción de los diques de embalse y las obras de irrigación sobre los ríos Cruz del Eje, Soto y Pichanas ${ }^{41}$. En líneas generales, el argumento que articulaba los programas de modernización destacaba aquellos elementos asociados al progreso económico y el crecimiento poblacional de una región tradicionalmente postergada por el Estado provincial.

\footnotetext{
${ }^{35}$ HLC. "Córdoba. Aguas corrientes en Cruz del Eje". (22 de septiembre de 1916), La Prensa, p. 5.

${ }^{36}$ HLC. "Córdoba. Aguas corrientes en Cruz del Eje". (22 de septiembre de 1916), La Prensa, p. 5.

${ }^{37}$ HLC "Córdoba. Vecinos de Cruz del Eje solicitarán varias obras de irrigación". (30 de julio de 1924), La Nación, p. 6.

${ }^{38}$ BLPC. Diario de Sesiones de la Cámara de Senadores, Legislatura Provincial. 1911, 25ํs sesión ordinaria: 9 de agosto de 1911. Proyecto sobre irrigación a Villa Cruz del Eje. Rodríguez de la Torre.

${ }^{39}$ Los argumentos sostenidos por los legisladores opositores giraban en torno a la exclusividad de los beneficios a un sector de la población de Cruz del Eje, quedando excluida la otra mitad de los ciudadanos.

${ }^{40}$ BLPC. Diario de Sesiones de la Cámara de Senadores, Legislatura Provincial. 1911, 25ํsosión ordinaria: 9 de agosto de 1911. Proyecto sobre irrigación a Villa Cruz del Eje. Rodríguez de la Torre.

${ }^{41}$ BLPC. Diario de Sesiones de la Cámara de Senadores, Legislatura Provincial. 1919, $10^{\circ}$ sesión ordinaria: 3 de julio de 1919. "Presentación y sanción de un proyecto sobre diques de embalses en los ríos Cruz del Eje, Soto y Pichanas".
} 
Giannone. El acceso diferencial a los recursos: El agua potable en el noroeste de Córdoba, Argentina (1912-1930).

Los planes de ejecución de las obras de irrigación en Cruz del Eje sentaron un importante antecedente en los procesos de gestión de la ciudadanía local -en cooperación con las autoridades locales- ante las instancias provinciales y eventualmente nacionales, por un plan de obras públicas para la región que excedía los límites circunscriptos del reclamo por el agua potable.

En 1924, durante la segunda gobernación de Cárcano, los vecinos de Cruz del Eje solicitaron nuevamente, a través de los intermediarios locales, varias obras de irrigación para la localidad. Esta demanda promovió el resurgir de la cuestión de los diques y de las necesarias obras de irrigación no solo para Cruz del Eje, sino para todo el noroeste. Así, en noviembre de ese año el Poder Ejecutivo de la provincia aprobó un amplio presupuesto en la construcción de obras públicas para los departamentos del norte, destinando para Cruz del Eje 80 mil pesos de los cuales un $20 \%$ se utilizaría para las obras de irrigación ${ }^{42}$.

Por su parte, no se puede perder de vista la "utilización política" del agua potable, que llevaba a los gobiernos provinciales a recurrir en reiteradas ocasiones a la extorsión o el chantaje a las autoridades departamentales y locales del signo político opuesto. La disputa por el control de las fuentes de aprovisionamiento de agua potable en el interior de la provincia, ${ }^{43}$ concretamente en Cruz del Eje, estaba atravesada por la conflictiva dinámica entre el oficialismo y la oposición.

En 1918, la prensa conservadora detallaba de qué manera el gobierno provincial de Julio Borda utilizaba políticamente el control de los recursos necesarios para la provisión de agua potable a Cruz del $\mathrm{Eje}^{44}$, extorsionando a los dirigentes de signo político opuesto ${ }^{45}$. Sin embargo, la práctica extorsiva no fue privativa del radicalismo. Por el contrario, para el matutino local de filiación radical La Voz del Interior, este procedimiento arbitrario había sido inventado y sistematizado por sus opositores demócratas y era uno de los recursos utilizados para torcer la voluntad política contra quienes no podía emplearse el machete, negando la distribución de agua a quienes no se incorporaban a las filas demócratas (Remedi, 2004: 20).

En esta dinámica, el rol de los partidos políticos fue clave en la articulación de las demandas sociales más acuciantes y como mecanismo de reclutamiento de las bases electorales a través de sus órganos políticos-partidarios de base.

Si bien durante la segunda década del siglo XX hubo una marcada pérdida del electorado demócrata en la localidad de Cruz del Eje, redundando en importantes

${ }^{42}$ HLC. "Córdoba. Programa de obras públicas". (12 de noviembre de 1924), La Prensa, p. 6.

${ }^{43}$ Remedi (2006) ha señalado la correlación existente entre la escasez del agua en el noroeste cordobés, notablemente inferior al resto de la provincia y su utilización política a los fines de manipular la voluntad popular a través de los mecanismos de coerción, chantaje y extorsión por parte de los dirigentes de uno u otro signo político.

${ }^{44}$ A partir de 1918, con la llegada del radicalismo a la primera magistratura provincial, Cruz del Eje se convirtió en un departamento controlado políticamente por intendentes de filiación radical, perdiendo los demócratas uno de los departamentos más importantes en términos electorales del noroeste cordobés.

${ }^{45}$ Biblioteca Nacional Mariano Moreno (en adelante BNMM). "La política del agua". (20 de septiembre de 1918), La Mañana, p. 3. 
beneficios para el radicalismo personalista, ${ }^{46}$ no dejaba de ser importante la presencia de dirigentes demócratas en la ciudad y la realización de actividades de propaganda por parte de sus comités locales.

En 1928, el Comité Departamental Demócrata realizó una importante conferencia pública que congregó a los obreros ferroviarios sobre las calles Rivadavia y San Martín. Más de 500 personas ocuparon el espacio público para escuchar la palabra de los delegados ferroviarios apoyando la fórmula demócrata Roca-Ceballos para la elección provincial, resaltando además "la importante acción de los gobiernos demócratas, traducida en múltiples obras públicas de capital importancia para sus pobladores"47.

Del eslogan del Comité demócrata se deprenden las propuestas encabezadas por los organismos de base partidarias con capacidad de reclutamiento de votantes durante las coyunturas eleccionarias, dándonos una imagen clara sobre los mecanismos políticos que articulaban esas demandas.

Por su parte, en la localidad de La Cumbre el entramado de relaciones incluía los vínculos que se configuraban entre diferentes escalas del poder político provincial y nacional en el marco de la iniciativa combinada de los vecinos y las autoridades locales que contaba con un gran potencial de movilización y de organización.

En los primeros años del siglo XX el Ministro de Obras Públicas de la provincia solicitó al director de salubridad de la nación, ingeniero Marcial R. Candiotti, la posibilidad de que le concedieran a "precio de costo" los materiales que necesitaba la localidad para proveerse de agua corriente ${ }^{48}$.

Aunque los representantes de los organismos estatales de las más altas esferas del poder político mostraban una especial preocupación por la localidad, fue decisiva la intervención simultánea de las autoridades departamentales y de los representantes estatales del gobierno provincial a través del Ministerio de Obras Públicas en la búsqueda de soluciones a la falta del servicio de aguas corrientes. Pero esa intervención no estaba exenta de tensiones y discrepancias entre los participantes.

Las diferencias entre el ingeniero responsable del estudio de los planes de ejecución para la instalación de aguas corrientes en La Cumbre y el intendente local resaltaban las vinculaciones entre agentes estatales locales y provinciales. A ellas le subyacía una desigualdad derivada de las asimetrías de poder, que respondía a la específica disposición de los sujetos en la red, y que además se reforzaba por el saber técnico y especializado que le otorgaba al ingeniero la suficiente legitimidad para tomar decisiones: ${ }^{49}$

\footnotetext{
${ }^{46} \mathrm{La}$ Voz del Interior detallaba los festejos realizados al frente de la Sociedad Española por más de 500 personas que exteriorizaban su alegría ante el triunfo avasallante en las elecciones provinciales del radicalismo personalista en Cruz del Eje. HLC. "El triunfo de la UCR en Cruz del Eje." (11 de febrero de 1918), La Voz del Interior, p. 3.

${ }^{47}$ AAC. "Conferencia ferroviaria en Villa Cruz del Eje", (15 de febrero de 1928), Los Principios, p. 7.

${ }^{48}$ HLC. "Aguas corrientes para La Cumbre”. (24 de octubre de 1916), La Nación, p. 6.

${ }^{49}$ Me refiero al capital cultural de estos sujetos en el marco de una sociedad moderna que reconocía en el "saber experto" una fuente de legitimidad de poder, otorgando estatus a quienes lo poseían y reforzando las desigualdades entre los agentes responsables de dar soluciones a los problemas de acceso al agua.
} 
Giannone. El acceso diferencial a los recursos: El agua potable en el noroeste de Córdoba, Argentina (1912-1930).

\begin{abstract}
"han surgido ciertas divergencias entre el intendente y el ingeniero encargado de practicar los estudios del caso. De la opinión del intendente participan muchos vecinos y aplauden su actitud pues se ha dirigido al Ministro de Obras Públicas con el fin de recordarles que las municipalidades, en cuya jurisdicción se efectúen obras que después pasarán a su dominio, deben ser oídas" ${ }^{\prime 50}$.
\end{abstract}

Del análisis del documento se desprenden elementos que responden a la dinámica política del reclamo. En primer lugar, los vínculos que se configuraban entre la "ciudadanía política" y la autoridad municipal nos revelan mecanismos de resistencia ${ }^{51}$ y los márgenes de negociación de los actores sociales que, interpelando a los poderes públicos estatales, discrepaban con los representantes del Estado Provincial, en este caso con el ingeniero. En segundo lugar, y vinculado con lo anterior, no se puede perder de vista las motivaciones e intencionalidades que subyacían al comportamiento de los individuos. La posición del intendente -que con especial énfasis resaltaba que las municipalidades deben ser oídas en los procesos de gestión- y el apoyo brindado por los habitantes de la localidad revela una trama de significados que excedía al específico reclamo y visibilizaba el común interés de las autoridades locales y los beneficiarios por definir las prerrogativas y los derechos del municipio en relación con el control y la administración del servicio público de aguas corrientes.

En 1917, los vecinos de La Cumbre ${ }^{52}$ junto al intendente y el presidente del Concejo Deliberante obtuvieron una audiencia con el gobernador Julio Borda y le reclamaron la ampliación del trazado de las tuberías de aguas corrientes para la localidad (obra que estaba en ejecución por un ingeniero contratista), ya que la misma -tal como había sido diseñada por los ingenieros de la Superintendencia de Irrigación de la provincia- impedía una distribución equilibrada del agua en los distintos puntos de la ciudad ${ }^{53}$.

Algunos conspicuos vecinos de la ciudad y el diputado Quinteros -representante del departamento Punilla- expusieron ante el Gobernador y el Jefe de la Oficina Provincial de Irrigación las razones que llevaban a modificar el error cometido en el trazado de las tuberías, destacando que debía haber una distribución más justa y equitativa del agua corriente en la ciudad para evitar un costo mayor a sus beneficiarios. Finalmente, las autoridades provinciales prometieron revisar y estudiar el pedido de la delegación.

${ }^{50}$ HLC. "En La Cumbre. Las aguas corrientes. Con motivo de la próxima instalación de las aguas corrientes en esta villa". (7 de noviembre de 1916), La Prensa, p. 3.

${ }^{51}$ Aquí recurro a la noción del antropólogo James Scott, quien la utiliza para referirse a las estrategias y prácticas cotidianas desplegadas por los sujetos para enfrentarse, sin abiertos cuestionamientos, a las estructuras de dominación. (Falcón, 2015, p.14).

${ }^{52}$ Entre quienes contaban con la participación del empresario local Domingo Minetti quien tenía intereses particulares en la región a través de la construcción de hoteles en la localidad.

${ }^{53}$ AAC. "Aguas corrientes de La Cumbre. Delegación Vecinal ante el Poder Ejecutivo". (22 de julio de 1927), Los Principios, p. 5. 
La explotación turística de localidad serrana desde las primeras décadas del siglo XX había colocado en el escenario político a nuevos sujetos con amplios intereses, principalmente económicos, ligados al desarrollo de un turismo de elite. El surgimiento de la hotelería en la región como parte de los intereses de la clase empresarial requería de un incremento sustancial en los gastos de infraestructura lo que implicaba, además la ampliación del servicio de aguas corrientes.

Como parte integrante y beneficiaria de esa elite, en 1926 Domingo Minetti encabezaba las gestiones necesarias para dar inicio a la construcción de un hotel dotado de todas las comodidades necesarias para convertir a La Cumbre en el lugar elegido por los turistas. Para tal fin se había concertado una reunión entre éste y las autoridades provinciales quienes se comprometían a estudiar la región y evaluar la posibilidad de ampliar la red de aguas corrientes, propiciando el desarrollo de la infraestructura hotelera ${ }^{54}$. A pesar de que el Gobierno de la Provincia había enviado a varios ingenieros de la Dirección General de Riego para estudiar la posibilidad de aumentar el caudal de agua del servicio yel que correspondía al arroyo denominado "Tío Mayo", la gran obra no se llevó a cabo al menos ese año.

Un año más tarde, con la reanudación de los planes de construcción del hotel, una Comisión de Vecinos encabezada nuevamente por Minetti solicitó al gobernador Cárcano la inmediata ampliación del servicio de aguas corrientes ${ }^{55}$.

De lo expuesto sobresale la trama de relaciones configurada por los agentes que ocupando diferentes niveles del poder político, exponían los motivos por los cuales debía realizarse una modificación en el diseño original de la instalación de aguas corrientes para La Cumbre, sin perder de vista que en la misma audiencia participaron ciudadanos de la localidad, lo que evidenciaba el interés de la población local por participar en los asuntos públicos de la ciudad.

Como parte de la lógica del reclamo por la instalación del servicio de aguas corrientes en la localidad serrana, resulta significativo el análisis del proyecto de ley sobre la transferencia de la administración del mismo que la provincia hizo al municipio en 1919 y la concomitante tensión que se generó a raíz de la superposición de intereses entre ambas escalas de poder político.

Dicha propuesta legislativa significaba un avance no desdeñable en la consolidación de la autonomía comunal, al menos en relación con el control local de los servicios públicos. Además, no se puede soslayar que en esa construcción legítima de la autonomía del estado municipal operó una dinámica vincular que ponía en relación a los representantes de los poderes legislativo y ejecutivo de la provincia con las prácticas de reclamo y movilización de la ciudadanía.

\footnotetext{
${ }^{54}$ HLC, "La provisión de agua dificulta la construcción del hotel de La Cumbre". (9 de abril de 1926), El Pais, p.9.

${ }^{55}$ Sobre los informes de Cárcano y los detalles de la aprobación del presupuesto ante el pedido de la Comisión encabezada por Minetti y las autoridades locales, consultar el diario El País entre abril de 1926 y julio de 1927.
} 
Giannone. El acceso diferencial a los recursos: El agua potable en el noroeste de Córdoba, Argentina (1912-1930).

La iniciativa de Rafael Núñez por retomar la cuestión relativa a las autonomías municipales se inserta en este entramado. En su discurso-programa de 1919, el Gobernador de Córdoba resaltaba que el control provincial que se ejercía sobre las municipalidades impedía su desenvolvimiento como entidad política. Aseguraba que su gobierno iba a avanzar en el reconocimiento de la plena autonomía de las comunas en la forma más amplia que prescribe la constitución- ${ }^{56}$.

En el recinto legislativo, el proyecto de ley del Ejecutivo provincial reforzaba las prerrogativas y los derechos del municipio. Aunque esta propuesta no se explayaba concretamente sobre las funciones de la comuna como entidad política. En su primer artículo reconocía una serie de prerrogativas específicas de las autoridades locales sobre los servicios públicos: El Poder Ejecutivo entregará en propiedad a la Municipalidad de La Cumbre, Departamento Punilla, la instalación de aguas corrientes y obras de riego construidas por el gobierno de la Provincia en dicha localidad ${ }^{57}$.

Por su parte, los artículos 5 y 6 revelaban la ambigüedad en torno a los beneficiarios directos de la administración del servicio de aguas corrientes, colocando a las autoridades locales en manifiesta desventaja en relación con su control. La provincia se encargaría de la supervisión de las obras de ampliación del servicio, mientras que el municipio debía utilizar el 50\% de sus ingresos para la cancelación de la deuda contraída con el Ejecutivo Provincial. Finalmente, el artículo octavo destacaba que, amortizada la deuda, la municipalidad de La Cumbre asumiría el dominio absoluto de las obras ${ }^{58}$.

En 1928 y a casi diez de la aprobación de la ley que reglamentó los mecanismos de administración y control comunal sobre el servicio de aguas corrientes, un nuevo acontecimiento asociado a la dificultad de garantizar el abastecimiento de agua potable a la localidad, reanudó la tensión existente entre la provincia y el municipio esta vez en relación a la administración del recurso hídrico ${ }^{59}$.

Las diferentes lecturas que realizaron los agentes estatales sobre los problemas reales que provocaron la falta de agua potable en La Cumbre respondían a los intereses de los beneficiarios directos de su control y administración. Mientras que el Intendente municipal sostenía que el principal problema radicaba en el levantamiento de las cañerías, el Gobernador remarcaba, apoyado en el informe realizado por el ingeniero, la deficiente y arbitraria administración municipal ${ }^{60}$.

La superposición de intereses del gobierno provincial y las autoridades locales se evidenció, una vez más, en la insistencia de aquel por reasumir la administración del

${ }^{56}$ HLC. "Discurso-programa de Rafael Núñez", (18 de mayo de 1919), Los Principios, p. 3.

${ }^{57}$ BLPC. Diario de Sesiones de la Cámara de Senadores, Legislatura Provincial, 1919. Presentación de un proyecto de ley, por el que el Poder Ejecutivo transferirá a la municipalidad de La Cumbre (Punilla), las obras de aguas corrientes de ese pueblo. Número 13. 10 sesión ordinaria: 3 de julio de 1919.

${ }^{58}$ BLPC. Diario de Sesiones de la Cámara de Senadores, Legislatura Provincial, año 1919. Presentación de un proyecto de ley, por el que el Poder Ejecutivo transferirá a la municipalidad de La Cumbre (Punilla), las obras de aguas corrientes de ese pueblo. Número 13. 10 sesión ordinaria: 3 de julio de 1919 .

${ }^{59}$ Con ello se alude a la concesión otorgada por el poder provincial al municipio sobre los derechos relativos a la administración del servicio de aguas corrientes en La Cumbre.

${ }^{60}$ HLC. "La Cumbre se quedará sin agua". (17 de enero de 1928), El País, p. 4. 
recurso hídrico, argumentando que el control del agua por parte de la provincia evitaba los problemas a los que se enfrentaba la población ante el faltante necesario para su consumo.

A través del análisis de las estrategias de gestión desplegadas por los vecinos de La Cumbre y sus acciones ante los poderes públicos provinciales es posible identificar la existencia de formas específicas y más estables de organización del reclamo realizado por la población local ${ }^{61}$. Aunque los orígenes de las sociedades de fomento pueden rastrearse por lo menos desde comienzos del siglo XX, ${ }^{62}$ el rol protagónico de la población de La Cumbre sentó las bases de una red más estable de trabajo colaborativo entre los ciudadanos contando además con una dinámica política relativamente democrática tanto en sus formas de organización como en los mecanismos que articulaban la toma de decisiones. Sobre esa base organizativa en 1930 se creó la Asociación de Vecinos de varias localidades para Fomento Serrano, conformada por varios pueblos de las Sierras (La Cumbre, Cruz Chica, Cruz Grande, Los Cocos, San Esteban y Dolores) y abocada a la tarea de promover los servicios públicos de la región, entre los que se destacaba el mejoramiento de la vialidad y la construcción de nuevos caminos ${ }^{63}$. La asociación contaba con una comisión directiva que realizaba asambleas periódicas para evaluar las necesidades de las localidades y diseñaba y planificaba las estrategias para resolver los problemas materiales de la región. Con el correr de los años, la sociedad de fomento se dedicó a propiciar el progreso económico serrano a través del desarrollo del turismo-. ${ }^{64}$.

\section{Consideraciones finales}

En este artículo se ha intentado reconstruir el comportamiento político de la población local y de los agentes estatales de las diferentes escalas de poder, dentro de una trama vincular que se configuraba para resolver los problemas más inmediatos del interior cordobés, en este caso -aunque no exclusivamente- el acceso y el abastecimiento del agua potable en el noroeste. Las prácticas que favorecieron la instalación del servicio de agua potable y su abastecimiento en las localidades estudiadas ponían en relación las distintas lógicas de los poderes políticos -en sus diferentes escalas- y de los beneficiarios.

\footnotetext{
${ }^{61}$ Algunos estudios que han indagado en torno a las prácticas de sociabilidad en todo el tejido social se inspiran en una línea de indagación abierta durante los años 70 por Maurice Agulhon (2009), quien ha abordado extensamente las múltiples formas de sociabilidad en Francia durante el proceso de formación de la burguesía. Siguiendo este sendero trazado por el historiador francés, Pilar González Bernaldo de Quirós (2007) ha trabajado en torno a las mutaciones de la sociabilidad y las prácticas sociales como parte de un fenómeno íntimamente vinculado a la política moderna. Por su parte, en Córdoba, las indagaciones en torno a la expansión del fomentismo durante la década del 20 se han centrado en analizar el fenómeno como parte de los procesos de urbanización y modernización social, enfocando su estudio en el surgimiento de asociaciones barriales en la ciudad de Córdoba (Vagliente, 2015) y en las ciudades con mayor concentración urbana como el caso de Río IV (Basconzuelo, 2005)

${ }^{62}$ El fondo documental de Gobierno conservado en el Archivo Histórico contiene importante y abultada información sobre los orígenes, la formación y la evolución de las sociedades de fomento durante todo el período que abarca este artículo.

${ }^{63}$ HLC. "Asociación de vecinos de varias localidades para fomento serrano". (28 de junio de 1930), La Prensa, p. 10.

${ }^{64}$ HLC. "Córdoba. Asociación de fomento serrano". (7 de marzo de 1931), La Prensa, p.10.
} 
Giannone. El acceso diferencial a los recursos: El agua potable en el noroeste de Córdoba, Argentina (1912-1930).

En este marco las actividades organizadas por los vecinos para reclamar por la instalación de un servicio de aguas corrientes contaban con diferentes estrategias de gestión, vinculadas a las múltiples formas de acercamiento entre los individuos que ocupaban posiciones desiguales en la red configurada para resolver sus problemas.

En Cruz del Eje, la demanda local contó con el apoyo de los legisladores tanto demócratas como radicales -aunque en este trabajo se ha analizado concretamente los proyectos de ley presentados por los diputados del Partido Demócrata- que debatían en el recinto parlamentario los proyectos de instalación del servicio de agua potable y el presupuesto que se destinaba para su concreción. Por su parte, la dinámica vincular se asociaba a prácticas y estrategias de articulación de las demandas sociales desplegadas por los partidos políticos en la región como parte de las diversas formas de reclutamiento del electorado.

Asimismo, en ocasiones el agua potable se convirtió en un recurso de extorsión utilizado por los gobiernos provinciales de signo político opuesto a las autoridades departamentales y municipales. Como se ha desarrollo en este artículo, la prensa conservadora y radical eran el principal instrumento de denuncia de las prácticas extorsivas a la que recurrían los gobiernos provinciales -tanto radicales como demócrataspara regular el abastecimiento, suministro y la distribución del agua potable.

En el caso de La Cumbre, principal centro turístico del Valle de Punilla, la capacidad agencial de los beneficiarios se vinculaba con las prácticas específicas de intervención de los representantes estatales de las más altas esferas del poder político. La presencia del Ministro de Obras Públicas de la Nación en la localidad serrana y la intervención simultánea de las autoridades municipales y provinciales respectivamente, sin perder de vista las redes de solidaridad de los vecinos de La Cumbre con las localidades aledañas, abrieron múltiples interpretaciones y mecanismos resolutivos.

No podemos perder de vista que, además, las estrategias y las prácticas articuladas de los vecinos respondían no solo a la búsqueda de un bien común para la localidad en su conjunto, sino que motivados por los incentivos selectivos, algunos vecinos se vieron particularmente beneficiados de la política de abastecimiento del recurso hídrico. Tanto en Cruz del Eje como en La Cumbre existían intereses que trascendían la lógica específica del reclamo por agua potable.

Desde un análisis del comportamiento económico que subyacía a la práctica del reclamo es posible observar de qué manera los pequeños productores de uva en Cruz del Eje se veían movilizados por sus propios intereses particulares, llevándolos a apoyar en 1911 el proyecto de ley del diputado demócrata Rodríguez de la Torre para la construcción del dique en la localidad. En La Cumbre, la intervención y activa participación de Domingo Minetti en las gestiones para garantizar el abastecimiento y posterior ampliación del servicio de aguas corrientes, se vinculaba concretamente con las ganancias económicas que tal extensión traería a Minetti en el marco del plan de desarrollo de una amplia hotelería en la región. En este sentido, el análisis de las prácticas de reclamo por agua potable no puede desvincularse -siguiendo la tesis de Olson sobre los incentivos selectivos- del comportamiento económico y por ende de los 
intereses personales y particulares que movilizaba a algunos ciudadanos a intervenir en los procesos de gestión por el acceso al agua potable.

Por su parte, la lente puesta en aquellos acontecimientos que revelaban la trama más amplia de significados del comportamiento de los actores sociales, permitió visibilizar tensiones y disputas políticas como parte de una desigualdad estructural que se reproducía en el ámbito local. Las prácticas de negociación y de resistencia que operaban en los procesos de gestión por el acceso al agua potable mostraron la complejidad del fenómeno estrictamente social, al abrir nuevos interrogantes sobre el comportamiento político de los sujetos. En este sentido, reveló las formas específicas y no tradicionales de ejercicio de la ciudadanía y los mecanismos que -en diálogo con el marco legal- configuraron una serie de prerrogativas y derechos del municipio, al menos en relación al control de los servicios públicos, prescindiendo de las autoridades provinciales.

Ambos procesos fueron visibles en los casos estudiados en este trabajo. De esta manera, y como parte de la demanda inicial, los vecinos activaron diferentes mecanismos y estrategias de resolución del problema, que incluían la elevación de petitorios al Poder Ejecutivo de la provincia o a sus intermediarios, la configuración de redes de solidaridad y la articulación de un conjunto de estrategias y mecanismos que en vinculación con las autoridades municipales, ampliaban los márgenes de negociación con los poderes estatales.

En suma, el estudio centrado en las prácticas y los mecanismos de instrumentación del servicio de aguas corrientes en ambas localidades, reveló los propósitos, los intereses y las motivaciones que subyacían detrás del reclamo, y la particular manera en que los sujetos experimentaron los beneficios y los costos de la modernización, las múltiples formas de ejercer la ciudadanía y los diversos mecanismos de interpelación de los partidos políticos a la población local.

Finalmente, y aunque no se haya abordado en este artículo, la presente indagación no pierde de vista la relevancia -a escala latinoamericana- de la problemática de acceso al agua potable y las estrategias resolutivas desplegadas por las elites estatales que articulaban las demandas sociales en torno a un conjunto de bienes y servicios distribuidos desigualmente en los espacios territoriales, trascendiendo la frontera estrictamente nacional del problema.

\section{Referencias bibliográficas}

Agulhon, M. (2009). El círculo burgués. La sociabilidad en Francia, 1810-1848. Buenos Aires: Siglo XXI.

Anuario de Estadísticas y Censos, Segundo Censo Nacional levantado el 10 de mayo de 1895, Tomo 2: Población, 1895.

Anuario de Estadísticas y Censos, Tercer Censo Nacional levantado el 1 de junio de 1914, Tomo 2: Población, 1916.

Archivo del Arzobispado de Córdoba, Los Principios Córdoba, Años 1914-1930. 
Auyero, J. (2001). La política de los pobres. Las prácticas clientelistas del peronismo. Buenos Aires: Manantial.

Ávila García, P. (Ed.). (2002). Agua, cultura y sociedad en México. México: El Colegio de Michoacán/Instituto Mexicano de Tecnología del Agua.

Barriera, D. (2002). "Por el camino de la historia política: hacia una historia política configuracional”. En: Secuencia. 56: 20-30.

Basconzuelo, C. (2005). La experiencia del vecinalismo en Río Cuarto desde sus comienzos a la actualidad. Río Cuarto. Córdoba: Barchiessi.

Biblioteca de la Legislatura de la Provincia de Córdoba, Diario de Sesiones de la Cámara de Diputados, Congreso Nacional, año 1915, tomo 2, 7: Provisión de agua potable a las Villas de Dolores y Cruz del Eje. Juan F. Cafferata y otros.

Biblioteca de la Legislatura de la Provincia de Córdoba, Diario de Sesiones Cámara de Diputados, Legislatura Provincial, año 1924, $12^{\circ}$ sesión ordinaria: 18 de abril de 1924. Presupuesto de obras de infraestructura.

Biblioteca de la Legislatura de la Provincia de Córdoba, Diario de Sesiones de la Cámara de Senadores, Legislatura Provincial, año 1911, 25º sesión ordinaria: 9 de agosto de 1911. Proyecto sobre irrigación a Villa Cruz del Eje. Rodríguez de la Torre.

Biblioteca de la Legislatura de la Provincia de Córdoba, Diario de Sesiones de la Cámara de Senadores, Legislatura Provincial, año 1919, 10 Sesión ordinaria: 3 de julio de 1919. Presentación y sanción de un proyecto sobre diques de embalses en los ríos Cruz del Eje, Soto y Pichanas; Presentación de un proyecto de ley, por el que el P.E transferirá a la municipalidad de La Cumbre (Punilla) las obras de aguas corrientes de ese pueblo.

Biblioteca Nacional Mariano Moreno, La Mañana, Buenos Aires, Años 1912, 1916, 1918.

Bragoni, B. (2004). Microanálisis. Ensayos de Historiografía Argentina. Buenos Aires: Prometeo.

De Privitellio, L. (2003). Vecinos y ciudadanos. Política y sociedad en la Buenos Aires de entreguerras. Buenos Aires: Siglo XXI.

Carbonetti, A. (2014). Fragmentos de la historia de la salud en la Argentina Rural, Eduvim: Villa María.

Castro, J. Kloster, K. y Torregrosa, M. (2004). "Ciudadanía y gobernabilidad en México: el caso de la conflictividad y la participación social en torno a la gestión del agua". En Jiménez, B. y Morán, L. (Eds.). El agua en México vista desde la Academia. México: Academia Mexicana de Ciencias.

Falcón, R. (2015). El jefe político. Un dominio negociado en el mundo rural del Estado de México, 1856-1911, México: El Colegio de México.

Garnero, G. (2014), "Río Chico de Nono: una historia del vínculo sociedad y río en el oeste cordobés 1870-1935". En: Estudios Rurales, 4, 6: 32-63.

Garnero, G. (2018). "La dialéctica sociedad/cuenca hidrográfica en el valle de traslasierra. Las aguas de Río Mina Clavero, Córdoba 1870-1935”. En: Temas Americanistas. 38: 23-35. ISSN: 1988-7868. 
Giannone, L. (2014). "El conservadurismo cordobés en los primeros años de la aplicación de la ley Sáenz Peña. (1912-1916)", tesis inédita de licenciatura en historia, Facultad de Filosofía y Humanidades, Universidad Católica de Córdoba, Córdoba.

González Bernaldo de Quirós, P. (2008). Civilidad y política en los orígenes de la nación argentina. Las sociabilidades en Buenos Aires, 1829-1862, Buenos Aires: Fondo de Cultura Económica.

Hemeroteca de la Legislatura de Córdoba, El País, Córdoba, Años 1926-1930.

Hemeroteca de la Legislatura de Córdoba, La Nación, Buenos Aires, Años 1912, 1916 , 1918, 1922, 1924, 1928, 1930.

Hemeroteca de la Legislatura de Córdoba, La Prensa Buenos Aires, Años 1916, 1918 , 1922, 1924, 1928.

Hemeroteca de la Legislatura de Córdoba, La Voz del Interior, Córdoba, Años 1914-1930. Isuani, F. (Ed.). (2011). Política pública y gestión del agua: Aportes para un debate necesario. Buenos Aires: Universidad Nacional de General Sarmiento.

Leyva Avila, J. (2013). “Tensiones por el uso del agua en el noroeste mexicano. El Valle del Yaqui. 1909-1919”. En: Anuario del Centro de Estudios Históricos. "Prof. Carlos S. A Segreti”, 13, pp. 17-34.

Martín, F. Rojas, F. Saldi L. (2010). "Domar el agua para gobernar. Concepciones sociopolíticas sobre la naturaleza y la sociedad en contextos de consolidación del Estado provincial mendocino hacia fines del siglo XIX y principios del XX". En: Anuario Centro de Estudios Históricos. "Porf. Carlos S.A Segreti”. 10, pp. 159-186.

Moretti, N. (2014). Buenos cristianos y honrados ciudadanos. La obra salesiana y la cuestión social. Córdoba, 1905-1930, Córdoba: Centro de Estudios Históricos. "Prof. Carlos S. A Segerti".

Moreyra, B. (1992). La producción agropecuaria cordobesa, 1880-1930 (cambios, transformaciones y permanencias), Centro de Estudios Históricos: Córdoba.

Moreyra, B. (2009). Cuestión social y politicas sociales en la Argentina. La modernidad periférica. Córdoba, 1900-1930. Bernal: Universidad Nacional de Quilmes.

Moreyra, B. (2015). <<Introducción>> En Cerdá J.M, Guadarrama G., Lorenzo M.D y Moreyra B. (comp.), El auxilio en las ciudades. Instituciones, actores y modelos de protección social. Argentina y México. Siglos XIX y XX (pp.3-20). Córdoba: Centro de Estudios Históricos "Prof. Carlos S.A Segreti”. Colegio Mexiquense.

Moreyra, B. (2017). "Modelo asistencial e historiografía en Argentina en la modernidad liberal". En: Quinto Sol, 3: 21-40.

Ortiz Bergia, María José. (2009). De caridades y derechos. La construcción de políticas sociales en el interior argentino. Córdoba (1930-1943), Córdoba: Centro de Estudios Históricos. "Prof. Carlos S. A Segreti".

Radovanivic, E. y Tartarini, J. (1999). Agua y saneamiento en Buenos Aires, 1580-1930. Buenos Aires: Patrimonio histórico 2, Aguas Argentinas.

Reguera, A. (2017). Vínculos que configuran redes. Las dimensiones relacionales de lo social y sus articulaciones a escalas diferenciadas, Buenos Aires: Teseo. 
Remedi, F. (2006). Dime qué comes y cómo lo comes y te diré quién eres. Una historia social del consumo en la modernización argentina. Córdoba, 1870-1930, Córdoba: Centro de Estudios Histórico. "Prof. Carlos S. A Segretti"

Remedi, F. (2006). "Estado y mercado en Córdoba. Consumo, riesgos sanitarios y regulaciones estatales: el mercado alimentario en la ciudad de Córdoba, 19151930", Anuario Centro de Estudios Históricos. "Prof. Carlos S.A Segreti", Córdoba, 6: 26-35. ISNN: 1666-6836.

Remedi F \& Barbosa C. M (2014). Cuestión social, políticas sociales y construcción del Estado Social en América Latina, Córdoba: Centro de Estudios Históricos "Prof. Carlos S. A Segreti”, Universidad Autónoma Metropolitana-Cuajimalpa. ISNN: 1666-6836.

Reygadas, L. (2008). La apropiación. Destejiendo las redes de la desigualdad, México: Anthropos.

Reygadas, L. (2004). "Las redes de la desigualdad: un enfoque multidimensional", Política y Cultura, 22: 40-55.

Ruffini M. \& Salomón A. (2013). Estado, políticas públicas y ciudadanía en el mundo rural, Buenos Aires: Imago Mundi.

Solveira, B. (2009). "El servicio de agua corriente en la ciudad de Córdoba (Argentina), 1880-1935". En 53 Congreso Internacional de Americanistas: México.

Sturla, M. (2010). "El acceso al agua: políticas públicas y problemáticas inherentes al proceso de descentralización administrativa. El caso de Río Ceballos", En: Solveira, B. Prescindencia e intervención. Relación retrospectiva entre Gobierno y Servicios Públicos, Brujas: Córdoba.

Vagliente, P. (2015). Asociativa, movilizada, violenta. La vida pública en Córdoba, 1850-1930. Tomo I. Villa María: Eduvim. 